\title{
Tumor Findings Supplemental Qualifiers Dataset
}

National Cancer Institute

\section{Source}

National Cancer Institute. Tumor Findings Supplemental Qualifiers Dataset. NCI

Thesaurus. Code C147257.

A dataset containing supplemental information, specifically non-standard variables, to parent records in the tumor findings domain. 